\title{
ATIVIDADE ORIENTADORA DE ENSINO: uma proposta à produção de significados em Geometria
}

\author{
CLOVIS LISBÔA DOS SANTOS JUNIOR \\ Universidade do Estado da Bahia (UNEB). Doutor em Educação Matemática e Tecnológica \\ (UFPE). Professor Titular do Curso de Licenciatura em Matemática, Campus X/UNEB. \\ ORCID: 0000-0003-1693-4484. E-mail: prof.clovislisboa@gmail.com

\section{LÍCIA DE SOUZA LEÃO MAIA} \\ Universidade Federal de Pernambuco (UFPE). Doutora em Sciences de Leducation - Université \\ de Paris V (Sorbone). Professora do Programa de Pós-graduação em Educação e do Programa \\ de Pós-graduação em Educação Matemática e Tecnológica. ORCID: 0000-0002-9525-3777. \\ E-mail: liciaslm@hotmail.com
}




\section{ATIVIDADE ORIENTADORA DE ENSINO: uma proposta à produção de significados em Geometria}

No presente artigo são apresentados os resultados de uma Atividade de Ensino aplicada futuros professores de Matemática com a finalidade de analisar a produção de significados dos participantes acerca do estudo de conceitos geométricos não euclidianos. A Teoria Histórico-Cultural, complementada pela Teoria da Atividade e a Atividade Orientadora de Ensino são os aportes teóricos que subsidiaram a investigação e as ações pedagógicas neste estudo. Assim, apoiamo-nos nos pressupostos teórico-metodológicos da Atividade Orientadora de Ensino como um desdobramento da perspectiva Histórico-Cultural, segundo a qual utilizamos como contexto para a negociação de significados entre os participantes. As informações foram captadas por meio da aplicação de uma proposta de intervenção envolvendo 15 licenciandos do curso de Matemática da Universidade do Estado da Bahia. Para a construção dos dados obtidos nesse estudo utilizamos os seguintes instrumentos: áudio gravações, Atividade de Ensino, diário de campo e relatórios individuais. O processo de internalização dos conceitos geométricos foi apreendido e analisado, utilizando-se como pressupostos duas categorias: o Conflito - da validade lógica à validade empírica; e a Ruptura - do espaço euclidiano para outros espaços, constituídas por meio das interações entre os participantes. Os participantes ao estudarem modelos geométricos não euclidianos atribuíram significados diferenciados para o conceito da soma de ângulos internos de um triângulo, ampliando assim, a compreensão desse conceito quando constituídos no modelo geométrico euclidiano. Concluímos que o estudo de diferentes modelos geométricos, na perspectiva da Atividade Orientadora de Ensino, promoveu o desenvolvimento do pensamento teórico dos licenciandos investigados tornando-se um caminho para a produção de significados no processo de ensino e aprendizagem da Geometria.

Palavras-chave: Atividade Orientadora de Ensino. Formação de professores. Geometrias não Euclidianas.

\section{TEACHING GUIDANCE ACTIVITY: a proposal for the production of meanings in Geometry}

In the present article the results of a Teaching Activity applied to future Mathematics, teachers presented in order to analyze the production of meanings of the participants about the study of non-Euclidean Geometric concepts. The Historical-Cultural Theory, complemented by the Activity Theory and the Teaching Guiding Activity are the theoretical contributions that supported the investigation and the pedagogical actions in this study. Thus, we rely on the theoretical and methodological assumptions of the Teaching Guidance Activity as an unfolding of the Historical-Cultural perspective, according to which we use it as a context for the negotiation of meanings between the participants. The information captured through the application of an intervention proposal involving 15 undergraduate students in the Mathematics course at the University of the State of Bahia. For the construction of the data obtained in this study, we used the following instruments: audio recordings, Teaching Activity, field diary and individual reports. The internalization process of geometric concepts captured and analyzed, using two categories as assumptions: Conflict - from logical validity to empirical validity; and the Rupture - from the Euclidean space to other spaces, constituted through the interactions between the participants. When

\section{plurais}


studying non-Euclidean geometric models, the participants attributed different meanings to the concept of the sum of the internal angles of a triangle, thus expanding the understanding of this concept when constituted in the Euclidean geometric model. We conclude that the study of different geometric models, in the perspective of the Teaching Guidance Activity, promoted the development of the theoretical thinking of the undergraduates investigated, becoming a path for the production of meanings in the teaching and learning process of Geometry.

Keywords: Teaching Guiding Activity. Teacher training. Non-Euclidean geometries.

\section{ACTIVIDAD DE ORIENTACIÓN DOCENTE: una propuesta para la producción de significados en Geometría}

En el presente artículo, se presentan los resultados de una Actividad de enseñanza aplicada a futuros maestros de Matemáticas para analizar la producción de significados por los participantes sobre el estudio de conceptos geométricos no euclidianos. La Teoría Histórico-Cultural, complementada por la Teoría de la Actividad y la Actividad de Orientación Docente, son los aportes teóricos que subsidiaron la investigación y las acciones pedagógicas en este estudio. Por lo tanto, confiamos en los supuestos teóricos y metodológicos de la actividad de orientación docente como un desarrollo de la perspectiva históricocultural, según la cual lo usamos como contexto para la negociación de significados entre los participantes. La información fue capturada mediante la aplicación de una propuesta de intervención que involucró a 15 estudiantes de pregrado en el curso de Matemáticas de la Universidad del Estado de Bahía. Para la construcción de los datos obtenidos en este estudio, utilizamos los siguientes instrumentos: grabaciones de audio, actividad docente, diario de campo e informes individuales. El proceso de internalización de conceptos geométricos fue arrestado y analizado, utilizando dos categorías como supuestos: Conflicto: de la validez lógica a la validez empírica; y la ruptura - del espacio euclidiano a otros espacios, constituido a través de las interacciones entre los participantes. Al estudiar modelos geométricos no euclidianos, los participantes atribuyeron diferentes significados al concepto de la suma de los ángulos internos de un triángulo, expandiendo así la comprensión de este concepto cuando se constituyó en el modelo geométrico euclidiano. Concluimos que el estudio de diferentes modelos geométricos, en la perspectiva de la Actividad de Orientación Docente, promovió el desarrollo del pensamiento teórico de los estudiantes universitarios investigados, convirtiéndose en un camino para la producción de significados en el proceso de enseñanza y aprendizaje de la Geometría.

Palabras clave: Actividad de Orientación Docente. Formación de profesores. Geometrías no Euclidianas. 


\section{ATIVIDADE ORIENTADORA DE ENSINO: uma proposta à produção de significados em Geometria}

\section{Introdução}

A escola é o principal mecanismo social responsável por aproximar os indivíduos com os objetos do mundo através da relação entre indivíduos, ou seja, o papel da escola é oportunizar, por meio da comunicação entre os indivíduos, a apropriação dos conhecimentos produzidos pelo homem.

No campo educacional, a apropriação dos conhecimentos científicos surge como um desafio para os profissionais envolvidos no processo de escolarização. Nessa perspectiva, Vygotsky (1987, p. 101) ressalta a importância da mediação para o processo de escolarização dos indivíduos ao colocar que "[...] o aprendizado adequadamente organizado resulta em desenvolvimento mental e põe em movimento vários processos de desenvolvimento que, de outra forma, seriam impossíveis de acontecer".

Ao pensarmos num processo de aprendizagem adequadamente organizado, é inevitável a associação do professor como agente principal do processo de escolarização, pois a sua atividade essencial está diretamente interligada à dos estudantes, que consiste na organização do ensino. Em outros termos, a função primordial do professor é organizar o ensino tendo em vista que os estudantes se apropriem dos conhecimentos produzidos historicamente pela humanidade.

Assim, o presente trabalho busca tecer reflexões acerca dos desafios relacionados ao desenvolvimento do conhecimento geométrico a partir da análise de significados produzidos por futuros professores de Matemática sobre o estudo de Geometrias não Euclidianas. Para tanto, apoiamo-nos nos pressupostos teórico-metodológicos da Atividade Orientadora de Ensino proposta por Moura (1996) como um desdobramento da perspectiva Histórico-Cultural (Vygotsky, 1987), segundo a qual utilizamos para organizar as ações pedagógicas durante a aplicação de uma proposta de intervenção almejando a negociação de significados entre os participantes da pesquisa.

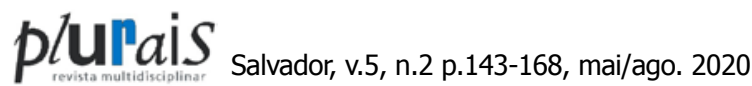




\section{Alguns Pressupostos Teóricos}

Este subtítulo tem como propósito apresentar os aportes teóricos da Teoria Histórico-Cultural (THC), Teoria da Atividade (TA) e dos pressupostos teórico-metodológicos da Atividade Orientadora de Ensino (AOE), para a elaboração da proposta de intervenção em que, sinteticamente, o planejamento das estratégias foram desenvolvidas considerando mediações pedagógicas em que sua orientação-execução-controle fossem base para a formação de conceitos sobre diferentes modelos geométricos. Assim, buscamos auxiliar os futuros professores de Matemática a procurarem uma consonância entre os seus motivos e necessidades em relação a apropriação do objeto em estudo. Para tanto, escolhemos alguns aspectos a serem desenvolvidos durante a proposta de intervenção:

- Caracterização dos futuros professores de Matemática em relação ao conhecimento da pluralidade de modelos geométricos (questionário diagnóstico);

- Elaboração de instrumentos pedagógicos para formação de conceitos geométricos (Atividade de Ensino e material manipulativo);

- Elaboração de atividades em grupo e individual;

- Utilização de signos e instrumentos variados nas orientações escritas e orais;

- Mediação entre professor-formador e participantes e entre os participantes;

- Elaboração de atividades com foco na generalização do conhecimento geométrico em estudo (níveis de aprofundamento).

A intenção ao desenvolver essas estratégias foi de buscar transformar a realidade dos participantes envolvidos neste processo de formação, a partir de instrumentos pedagógicos que lhes possibilitem a apropriação de diferentes modelos geométricos, por meio de interações promovidas pelo diálogo, com o intuito de ampliar a compreensão de conceitos geométricos euclidianos e não euclidianos. Portanto, a ação age como mola propulsora da prática, que por sua vez constrói conhecimento e alcança seu ápice na transformação do saber dos participantes no processo.

\section{plurais}


A organização do ensino do ponto de vista da AOE coloca a aprendizagem em uma posição de destaque na atividade - ensino, pois tanto o professor, quanto os estudantes estarão mobilizados para a apropriação de conhecimentos. A AOE torna-se a unidade de formação entre professor e alunos, pois o professor ao organizar o processo de ensinar, também, qualifica seus conhecimentos, produzindo novos sentidos e significados para o desenvolvimento de práticas pedagógicas diferenciadas, que podem gerar e promover a atividade do estudante: estudar e aprender teoricamente sobre a realidade (MOURA ET AL, 2010).

Assim, para que a AOE se torne uma unidade de formação entre professor e alunos, se faz necessário estabelecer uma correspondência de modo que os motivos, intenções, objetivos, ações e condições possam se relacionar de maneira processual na realização da atividade pedagógica.

Nessa perspectiva, o participante ao se apropriar do conhecimento teórico sobre os diferentes modelos geométricos passa a ter condição de atribuir novos significados para os conceitos geométricos já internalizados sobre a realidade em que vive, ampliando e modificando os seus modos de interagir com a realidade que lhe é sensível, o que "[...] permite a ele transformar a forma e o conteúdo do seu pensamento" (ROSA ET AL., 2010, p. 67).

Lopes e Vaz (2014), apontam que a relação estabelecida entre AOE e o conceito de atividade proposto por Leontiev (1978), está alicerçada na natureza da atividade humana como fonte geral do desenvolvimento das funções psicológicas superiores. Assim, a tríade defendida pela Teoria Histórico-Cultural está presente nessa relação, na qual “[...] temos um sujeito histórico (aluno), um objeto social (determinado conhecimento/conceito/conteúdo) e uma mediação cultural - o professor, seus saberes, produção cultural, a organização do ensino" (ARAÚJO, 2003, p. 28).

Para Daniels (2003) o objetivo dos teóricos da atividade é analisar os impactos psicológicos da atividade organizada, considerando as condições e sistemas gerados em e por tal atividade. Assim, a atividade social prática se torna unidade de análise para o desenvolvimento da consciência.

Dessa maneira, Leontiev (1988, p. 68) no contexto da TA define a atividade da seguinte forma:

\footnotetext{
plupais 
[...] aqueles processos que, realizando as relações do homem com o mundo, satisfazem uma necessidade especial correspondente a ele [...]. Por atividade, designamos os processos psicologicamente caracterizados por aquilo a que o processo, como um todo, se dirige (seu objeto), coincidindo sempre com o objeto que estimula o sujeito a executar esta atividade, isto é, o motivo.

Moura et alli. (2010) coloca que a TA pode fundamentar o trabalho do professor na organização do ensino, ao passo que se trata de uma ação que deve estar voltada intencionalmente para a apropriação de conhecimentos produzidos historicamente, concretizando, assim, os objetivos sociais do currículo escolar. A organização do ensino é considerada como atividade na concepção dos autores por implicar que o professor deve definir ações (que considerem as condições objetivas da escola), eleger instrumentos (processos de mediação dos sujeitos com os objetos), avaliar o processo de ensino e aprendizagem (objetivos relacionados ao ensinar e aprender) e por fim, constatar a apropriação dos conhecimentos historicamente acumulados pelos discentes (necessidade/motivo).

Com base nos pressupostos da TA, Moura (2010) desvela que a atividade ensino do professor deve produzir e promover a atividade do estudante. O envolvimento do professor com sua atividade ensino pode auxiliá-lo a tomar consciência de seu próprio trabalho e de seu objeto de ensino, o produto do processo de construção do saber será transformado em objeto de aprendizagem para os estudantes. Assim, na organização do ensino, o professor também exerce ações que promovem os conhecimentos teóricos em jogo, tornando-os em objeto e necessidade de sua atividade de aprendizagem, o que simultaneamente cria no estudante a necessidade de se apropriar do conceito em questão.

Na confluência com as teorias apresentadas até aqui recorremos ao princípio histórico-cultural da atividade como mecanismo teórico-metodológico para problematizar a prática pedagógica e, consequentemente, atribuir significados à atividade ensino, tendo como unidade de investigação inicial a necessidade de organizar o trabalho pedagógico de "[...] maneira que os sujeitos interajam entre si e com o objeto de conhecimento" (MOURA, 2002, p. 159).

Moura (2002) define o ensino como uma atividade que deve envolver o aluno num processo reflexivo a partir da vivência de situações-problema que produzam a necessidade do desenvolvimento de significados próprios do conceito em jogo. Para o autor (2002, p. 155) uma AOE pode ser definida como:

\section{plurais}


[...] aquela que se estrutura de modo a permitir que sujeitos interajam, mediados por um conteúdo, negociando significados, com o objetivo de solucionar coletivamente uma situação-problema. É atividade orientadora porque define elementos essenciais da ação educativa e respeita a dinâmica das interações que nem sempre chegam a resultados esperados pelo professor. Este estabelece os objetivos, define as ações e elege os instrumentos auxiliares de ensino, porém não detém todo o processo, justamente porque aceita que os sujeitos em interação partilhem significados que se modificam diante do objeto de conhecimento em discussão.

Logo, no coração da AOE encontra-se a situação problema como aspecto desencadeador da necessidade que levou o homem à construção de determinado conceito, promovendo o compartilhamento de significados e experiências entre os estudantes, num ambiente que busca, de forma coletiva, as soluções para a situação-problema, na qual possibilita a troca e a produção de conhecimentos entre os envolvidos no dinâmico processo de ensino e aprendizagem. Assim, a AOE se configura por meio da intencionalidade do educador ao articular instrumentos e estratégias que permitirão a produção de significados dos sujeitos com o objeto de conhecimento (MOURA, 1996).

Nessa perspectiva, Moura $(1996 ; 2010)$ pontua três aspectos imprescindíveis para estrutura da AOE: a síntese histórica do conceito que possibilita o professor apropriar-se do aspecto pedagógico da história do conceito; a situação-problema ou a situação desencadeadora de aprendizagem que deve contemplar a gênese do conceito e pode ser materializada de maneiras diferentes, na qual apresenta três recursos metodológicos: os jogos, as situações que emergem do cotidiano e a história virtual do conceito; a síntese coletiva que é a solução "matematicamente correta" da situação-problema desenvolvida pelos estudantes em coletividade.

No viés das concepções trazidas, o presente estudo centra-se na formação inicial de professores de Matemática, compreendendo a importância da problematização das ações pedagógicas do professor, uma vez que busca por meio de situações de vivência e exploração de Atividades de Ensino desenvolver as funções psíquicas dos estudantes, futuros professores de Matemática, acerca do estudo de Geometrias não Euclidianas como uma maneira de ampliar os conhecimentos no campo geométrico e, consequentemente, ressignificar o ensino de Geometria.

A seguir, iremos analisar os elementos estruturantes da AOE na perspectiva de compreender melhor as suas peculiaridades, bem como, as suas possíveis contribuições para o processo de formação de futuros professores de Matemática.

\section{plupais




\section{Síntese histórica do conceito}

Para compreender o lugar que ocupa o conhecimento histórico na $\mathrm{AOE}$, recorremos aos dizeres de Nascimento (2010) tendo-a como base teórica de pesquisa, por se apoiar nos pilares teóricos da TA, isto é, ao pensar a organização do ensino enquanto atividade e, consequentemente, como objeto de pesquisa. É considerada também, como base metodológica ao se constituir como instrumento lógico-histórico para a organização dos conhecimentos no processo de ensino e aprendizagem.

Para Moura et al. (2010), a situação-problema ou a situação desencadeadora de aprendizagem deve ser constituída da essência do conhecimento em questão, relacionando-a ao modo "[...] como foram aparecendo os problemas e as necessidades humanas em determinada atividade e como os homens foram elaborando as soluções ou sínteses no seu movimento lógico-histórico" (MOURA ET AL., 2010, p. 103-104).

Moretti (2007, p. 97) ressalta a importância do movimento lógico-histórico para a construção teórica do conhecimento ao aduzir que:

[...] compreender a essência das necessidades que moveram a humanidade na busca de soluções que possibilitaram a construção social dos conceitos é parte do movimento de compreensão do próprio conceito. Assim, o aspecto histórico associa-se ao aspecto lógico no processo de conhecimento de um determinado objeto de estudo e é só nessa unidade dialética que o conhecimento desse objeto é possível.

Desse modo, a história do conceito deve permear a organização das ações do professor, principalmente o que ensina Matemática, de maneira que possa propor aos seus estudantes problemas desencadeadores que contenham em si a essência do conceito. Segundo Kopnin (1978, p. 186) a unidade entre o lógico e o histórico do conceito para a compreensão do conceito faz-se necessária uma vez que o “[...] lógico reflete não só a história do próprio objeto como também a história do seu conhecimento".

Nesse entendimento, Moura (1996) compreende a importância do movimento lógico-histórico para a formação de conceitos pelo indivíduo, inserindo essa perspectiva metodológica de produção de sentidos e significados acerca de determinado objeto como elemento inicial da AOE. 
Então, na organização do ensino, o autor propõe que o movimento lógico-histórico se constitui na perspectiva da AOE pela realização da síntese histórica do conceito, que possibilita o professor apropriar-se do movimento lógico-histórico de constituição do conceito a ser trabalhado em sala de aula e, consequentemente, ter uma visão dinâmica de sua construção, compreendendo também as necessidades sociais de sua produção.

Para Moura (1996), esse elemento contribuirá para que o professor possa elaborar a situação desencadeadora de aprendizagem da AOE. É na compreensão da essência do conceito que o professor encontrará a autonomia necessária para estabelecer relações sociais para a criação e a solução de problemas. A síntese histórica do conceito, na perspectiva aqui apresentada, pode corroborar para a prática docente ao criar condições para o professor assumir a posição de autoria na construção do conhecimento, potencializando as suas ações ao planejar, executar e avaliar as atividades de ensino.

Nessa perspectiva, assumimos a síntese histórica do conceito como um recurso indispensável para a organização e desenvolvimento de ações metodológicas da AOE, que orientou, no caso deste estudo, as nossas investigações acerca do estudo de Geometrias não Euclidianas na formação de futuros professores de Matemática e suas implicações pedagógicas para a prática docente.

\section{Situação desencadeadora de aprendizagem}

Na perspectiva histórico-cultural, o problema surge no processo de ensino e aprendizagem no sentido de provocar a elaboração de situações-problema de aprendizagem que embutam em si a necessidade do conceito. Para Saviani (2000, p. 21), a constituição de um problema está intrinsicamente ligado a sua necessidade, assim

A essência do problema é a necessidade. [...] Assim, uma questão, em si, não caracteriza o problema, nem mesmo aquela cuja resposta é desconhecida; mas uma questão cuja resposta se desconhece e se necessita conhecer, eis aí um problema. Algo que eu não sei não é problema; mas quando eu ignoro alguma coisa que eu preciso saber eis-me, então, diante de um problema.

Moretti (2014) em consonância com as ideias de Saviani (2000) propõe que a situação-problema prediz uma primeira aproximação do estudante com o objeto de saber, na qual o problema

\footnotetext{
plupais 
designa processos que satisfazem a sua necessidade, criando condições para que o sujeito que aprende se aproprie do conhecimento historicamente construído pelo homem, humanizando-se.

Pelo contextualizado, ao pensarmos na organização do ensino, o professor de Matemática tem como desafio propor problemas que coloquem para os estudantes situações desencadeadoras de aprendizagem que ao serem resolvidas pelos mesmos provoquem a apropriação e a objetivação dos elementos essenciais do conhecimento que se pretende ensinar.

Moura (1996) defende à necessidade de o professor realizar a síntese histórica do conceito como um caminho para superar o desafio imposto ao docente de propor problemas que realmente se constituam em situações desencadeadoras de aprendizagem. Nesse sentido, o professor visando uma aprendizagem significativa dos conceitos que quer ensinar deve partir de situações-problemas que sejam significativas para o estudante, podendo ser materializadas por meio de diferentes recursos metodológicos, dentre os quais se encontram os jogos, as situações emergentes do cotidiano e a história virtual do conceito.

Para melhor compreender os recursos propostos por Moura (1996), nos apoiamos na sistematização proposta por Vaz (2013, p. 39).

Figura 1 - Recursos da Atividade Prientadora de Ensino

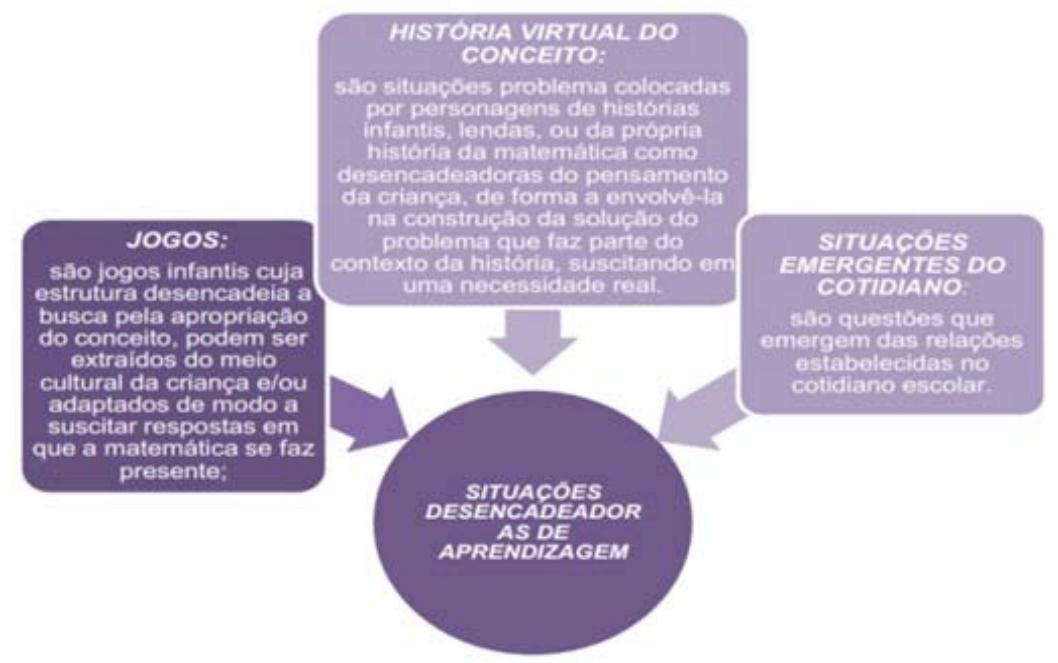

Fonte: Vaz (2013). 
A finalidade principal das situações desencadeadoras de aprendizagem consiste em envolver o estudante na busca da solução de um determinado problema, de modo a satisfazer uma determinada necessidade, que pode justificar a sua produção em certo momento histórico da humanidade.

\section{Sintese coletiva}

A síntese coletiva se configura como a última ação proposta pela AOE, em que a solução da situação-problema deve ser elaborada pelos estudantes coletivamente. Dessa maneira, pensando na organização do ensino, cabe ao professor elaborar atividades de ensino que imbriquem os estudantes num processo de busca coletiva da solução.

Segundo Moysés (1997) os estudos por meio de atividade compartilhada ou atividade grupal se inserem, principalmente, em duas linhas de pesquisas:

[...] a dos que procuram saber de que maneira as formas coletivas de organização das atividades de aprendizagem contribuem para o desenvolvimento das funções mentais superiores, e a dos que, ao analisá-las, se preocupam mais em saber de que forma elas favorecem à aquisição de conhecimento (MOYSÉS, 1997, p. 57).

O compartilhamento de ações e ideias entre os indivíduos se caracteriza no terceiro elemento da AOE, na qual Moura (1996) denomina de síntese coletiva, que tem a finalidade de encontrar a solução "matematicamente correta" da situação desencadeadora de aprendizagem elaborada em coletividade pelos estudantes.

Pozebon et al. (2013, p. 5) reflete na aplicabilidade auferida através da mediação do professor pela síntese coletiva quando esta é desenvolvida pelos estudantes trazendo efetivas ponderações acerca da mesma, perebendo que:

[...] a turma deverá chegar a uma resposta comum a todos e "matematicamente correta" para o problema. Essa resposta deve estar relacionada e coincidir com a construção histórica do conceito, por isso, a consideramos como "matematicamente correta". A ação do educador torna-se essencial neste momento de compartilhamento de ações e ideias, em que todos devem chegar a uma solução semelhante àquela historicamente vivenciada pelo homem.

\footnotetext{
plurais 
De maneira sucinta, Lopes e Vaz (2014, p. 1023) explanam que "[...] a síntese coletiva refere-se à solução da situação problema na AOE que deve ser realizada na coletividade, a partir de situações que exigem o compartilhamento de ações".

Do ponto de vista da organização do ensino, a síntese da solução em coletividade se torna um dos momentos mais delicados para o professor, pois os discentes vão expor as ideias elaboradas como possível resposta para a situação-problema e por meio do conflito entre as mesmas deve-se encontrar uma solução em consenso.

O papel do docente neste momento é essencial, cabe a ele mediar a situação de modo a conduzir os estudantes para uma construção coletiva que visa encontrar a solução mais adequada do problema proposto, sem propor a solução imediata, mas sim, levantar hipóteses e questionamentos que possam fazer emergir reflexões nos discentes a partir das ideias expostas, podendo modificá-las e aprimorá-las, a ponto de formalizar os conceitos envolvidos e encontrar a melhor solução para a situação desencadeadora em questão.

\section{Descrição do experimento realizado com os futuros professores de Matemática}

O trabalho foi desenvolvido com licenciandos em Matemática da Universidade do Estado da Bahia - UNEB/Campus X, localizada na cidade de Teixeira de Freitas na Bahia. A priori, a proposta foi de cunho teórico-prático e teve a finalidade de construir documentos para o estudo que permitam analisar a produção de significados de futuros professores de Matemática, a partir da vivência e exploração de Atividades de Ensino sobre diferentes modelos geométricos.

Os dados foram coletados durante a aplicação de um projeto de intervenção que teve 7 encontros com a duração de 3 horas cada, em que foram utilizados os seguintes instrumentos de coleta de dados: questionário diagnóstico, Atividades de Ensino, gravações áudiovisuais e o roteiro de observação.

As Atividades de Ensino foram construídas a partir dos pressupostos teórico-metodológicos da AEO e utilizadas como contexto para estimular a negociação de significados de futuros professores de Matemática acerca do estudo de conceitos de Geometrias não Euclidianas. 
Os participantes foram divididos durante a participação na pesquisa em 4 grupos com 4 integrantes cada, e, se auto denominaram: Licenciandos do grupo Beta (LB 1, LB 2, LB 3, LB 4); Licenciandos do grupo Delta (LD 1, LD 2, LD 3, LD 4); Licenciandos do grupo Geodésicos (LG 1, LG 2, LG 3, LG 4); Licenciandos do grupo Os Quatro Postulados (LO 1, LO 2, LO 3, LO 4).

Para identificar no processo de categorização a origem dos dados dessa pesquisa, denotamos a seguinte codificação: L (acompanhado da letra do grupo e o número) - Licenciando e o grupo que pertence; AE (acompanhado do número) - Atividade de Ensino; PP - Professor Pesquisador; RI (acompanhado do número) - relatório individual.

Neste artigo abordaremos a produção de significados dos participantes que foram captadas a partir da aplicação da Atividade de Ensino intitulada "A soma dos ângulos internos de um triângulo qualquer é sempre $180^{\circ}$ ?".

Atividade de Ensino: A soma dos ângulos internos de um triângulo qualquer é sempre $180^{\circ}$ ?

A Atividade de Ensino (AE) serviu como fio condutor para a construção de um espaço de negociação de significados sobre diferentes modelos geométricos que se constituíram a partir das discussões, diálogos e reflexões produzidas pelos licenciandos e pelo professor-pesquisador. $\mathrm{O}$ processo de construção dos conhecimentos geométricos foram investigados a partir da necessidade de sua produção, analisando as limitações do modelo geométrico euclidiano para que emergisse novas formas de perceber e compreender o espaço em que vivemos.

Segue abaixo a representação da AE. 
Clovis Lisbôa dos Santos Junior e Lícia de Souza Leão Maia

Figura 2: AE - A soma dos ângulos internos de um triângulo qualquer é sempre $180^{\circ}$ ?

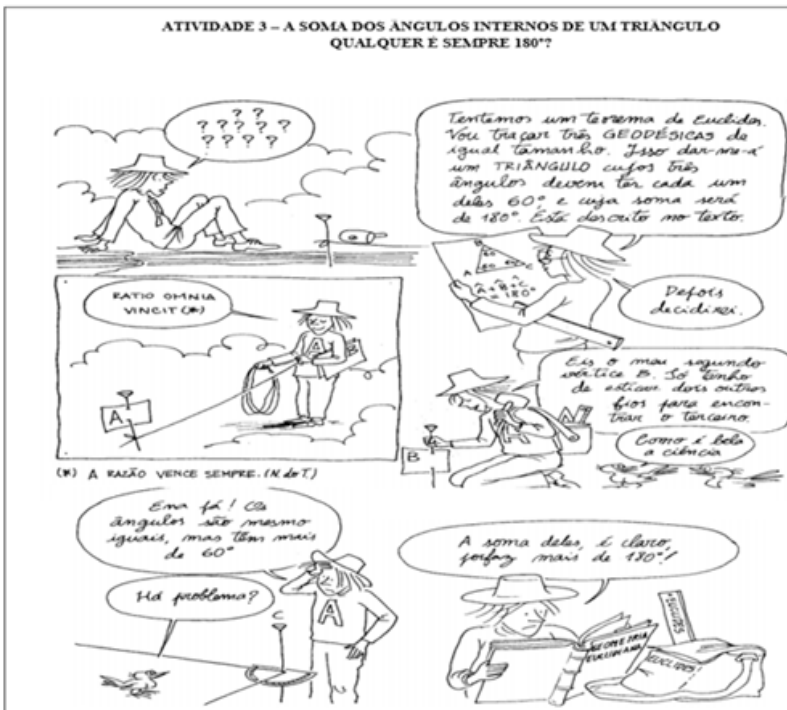

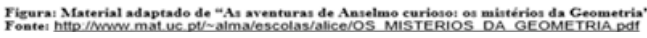
Considerando a tituaçào vivenciada por Anselmo, explique o que pode estar ocorrendo com o teorema de Euclides sobre a soma dos ingulos internos de um triàngulo para que este nào funcione no mundo de Anselmo.

Vamos realizar dois experimentos para compreendermos melhor a situaçăo vivenciada pelo Anselmo. Experimento I

a) Verificar se a soma dos àngulos internos de um triingulo é igual a 180\%.

- Corte um triangulo de uma folla de papel.

Pinte cada ingulo do triingulo de uma cor diferente.

Dobre esse triangulo ao "meio", paralelo a um dos lados juatando um vértice ao lado oposto (um jeito de fazer ficar bem paralelo é dobrar nos pontos médios dos lados).

A gora dobre perpendicular à base, juatando com o ingulo da dobradura anterior.

Agora dobre perpendicular i base, juntando o com o ingulo da $1^{*}$ dobradura.

b) Qual a conclusão a que rocè chẹa com relação à soma dos ângulos internos de um trìngule? Justifique sua resposta.

c) Que relaçóes podemos estabelecer entre a construção proposta no item a e 0 V Postulado de Euclides?

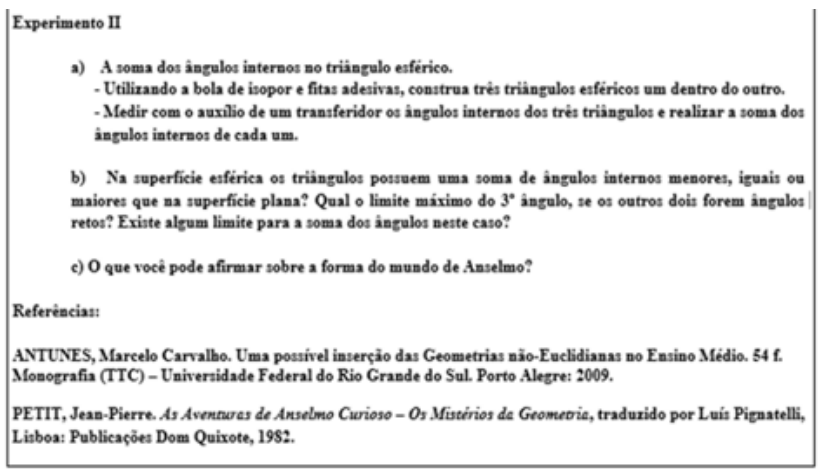

Fonte: Autor (2018).

\section{plurais}


As AE foram pensadas a partir dos conhecimentos geométricos prévios dos participantes, de maneira que a interação entre o licenciando e os conteúdos abordados fossem se desenvolvendo por meio de um processo investigativo que articulou os conceitos em níveis de aprofundamento, ou seja, todas as AE eram interligadas e a compreensão dos conceitos de uma se tornava pré-requisito para a realização da outra. As AE focaram na generalização do conhecimento geométrico em estudo.

\section{Aspectos constitutivos da produção de significados geométricos sobre o estudo de diferentes Geometrias}

A partir da leitura cuidadosa e aprofundada do material das observações, do registro escrito produzido pelos participantes e das transcrições dos eventos ocorridos nos encontros, realizamos o agrupamento das informações por meio de conteúdos semelhantes, complementares ou contradição, de maneira a apreender a produção de significados dos futuros professores de Matemática sobre conceitos fundamentais das Geometrias Não Euclidianas. A triangulação dos dados fizeram emergir as seguintes categorias de análise: "Conflito - da validade lógica à validade empírica" e "Ruptura - do espaço euclidiano para outros espaços".

A categoria "Conflito - da validade lógica à validade empírica" se manifesta primeiramente no conhecimento prévio do participante, quando este assume a Geometria Euclidiana como um sistema logicamente consistente, considerando-o como a única forma de interpretar e representar o espaço físico real. E se completa quando o participante compreende que a validade empírica do conhecimento geométrico euclidiano depende do contexto em que é utilizado. Já a categoria "Ruptura - do espaço euclidiano para outros espaços" se manifesta quando há o rompimento do paradigma de uma única Geometria, ou seja, na aceitação de modelos geométricos não euclidianos e no movimento de construção de novos conhecimentos a partir dessa compreensão.

Apresentaremos a seguir em forma de episódio alguns momentos dos encontros formativos cuja discussão coletiva sobre o estudo de GNE se fez presente.

\section{plurais




\section{Análise da produção de significados dos participantes no desenvolvimento da atividade de ensino}

Este episódio é um recorte do terceiro encontro da aplicação da proposta de intervenção que aconteceu no dia 11 de maio de 2019. O episódio tem sua estrutura captada no momento da plenária da $\mathrm{AE}$ e destacamos o movimento dos licenciandos na construção de triângulos na superfície esférica.

No Episódio 4 observamos que a categoria "Ruptura" é a que se manifesta de predominantemente, uma vez que fica claro no movimento realizado pelos participantes ao desenvolverem a AE que houve a aceitação por parte dos mesmos da existência de modelo geométrico não euclidiano e passam a construir novos conceitos geométricos não somente considerando as limitações dos conhecimentos geométricos euclidianos, como também relacionando seus conhecimentos geométricos diretamente com a superfície em estudo. A aceitação do modelo geométrico esférico evidencia o rompimento com a estrutura lógica da Geometria Euclidiana, exigindo dos participantes novas formas de pensar e agir no processo de construção de conceitos geométricos.

Na Cena 1 apresentamos o movimento dos licenciandos ao verificarem que a soma dos ângulos internos de um triângulo esférico é maior que $180^{\circ}$.

Cena 1: Discussão sobre a construção de triângulo esférico

$P P$ - Considerando a situação vivenciada por Anselmo, explique o que pode estar ocorrendo com conceitos de Euclides, sobre a soma dos ângulos internos do triângulo para que não funcione no mundo de Anselmo.

LO 4 - A gente colocou que a demonstração de Euclides é feita no plano e Anselmo está fazendo na Terra, né. Então vai dar diferença já que é uma esfera.

LB 3-O porquê a gente não conseguiu. Mas fizemos um monte de triângulos (na bola de isopor) que a soma dos ângulos deram duzentos e tantos graus. Que deu assim ... 80 $80^{\circ}$ um vértice, $80^{\circ}$ no outro e $90^{\circ}$.

$P P-O$ que o grupo LG respondeu?

LG 1 - Que a soma sempre está dando maior que $180^{\circ}$.

$P P$ - Então, dar sempre maior que $180^{\circ}$ é um furo na consequência do V postulado de Euclides, da dedução do Postulado de Euclides que diz que a soma dos ângulos interno de um triângulo tem que dar $180^{\circ}$.

Fonte: Dados da pesquisa - Episódio 4. 
$\mathrm{Na}$ discussão o grupo LO coloca como perspectiva de análise inicial o tipo de superfície que está em jogo argumentando que "A gente colocou que a demonstração de Euclides é feita no plano e Anselmo está fazendo na Terra, né? Então vai dar diferença já que é uma esfera." (LO 4, Episódio 4, 2019). Nesse momento compreendemos que os participantes não desenvolveram argumentos a partir do questionamento da ideia de que a soma dos ângulos internos de um triângulo qualquer na superfície plana é sempre igual a $180^{\circ}$ como demonstrado por Euclides. A aceitação do modelo geométrico esférico proporcionou aos licenciandos novas maneiras de pensar e agir durante a construção do saber, uma vez que possibilitou a atribuição de significados diferentes ao concluírem que um triângulo esférico tem a soma dos seus ângulos internos maior do que $180^{\circ}$.

"O porquê a gente não conseguiu. Mas fizemos um monte de triângulos (na bola de isopor) que a soma dos ângulos deram duzentos e tantos graus. Que deu assim ... 80 $80^{\circ}$ num vértice, $80^{\circ}$ no outro e $90^{\circ}$." (LB 3, Episódio 4, 2019).

"Que a soma sempre está dando maior que 180․" (LG 1, Episódio 4, 2019).

Na Figura 3 denotamos a construção - realizada pelo grupo LB - de triângulos esféricos na bola de isopor e o processo de aferição dos ângulos nesses objetos.

Figura 3 - Construção de triângulos em superfície esférica.

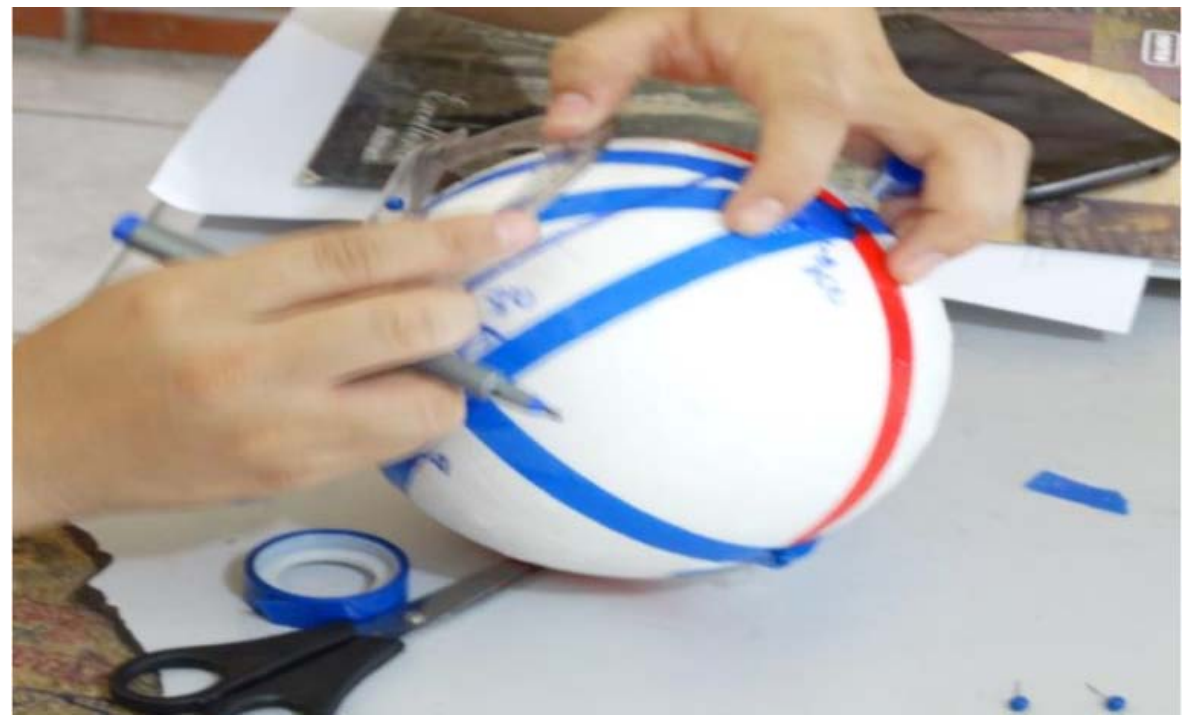

Fonte: Dados da pesquisa (2019).

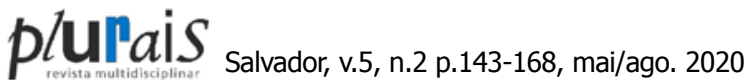


Na Cena 2 abordamos o movimento dos participantes na primeira parte da oficina de construção de um triângulo qualquer em uma folha de papel A4. O objetivo da realização desse experimento foi o de articular a construção de triângulos na superfície plana como uma consequência do paralelismo entre retas na Geometria Euclidiana.

Cena 2: Discussão sobre a construção de triângulos na superfície plana

PP - Vocês realizaram dois experimentos. A primeira oficina vocês montaram um triângulo qualquer. Qual é a conclusão que vocês chegaram sobre a soma dos ângulos internos do triângulo em uma folha de papel?

LB 1 - Que a soma dá um ângulo raso.

LO 4 - A soma dos ângulos internos vai dar sempre $180^{\circ}$.

LB 3 - Chegamos até na ideia de retas paralelas.

LO 4 - A gente percebeu que são duas paralelas (mostrando a construção do triângulo realizado pelo grupo na folha de papel). Colocamos assim: qualquer triângulo construído entre duas paralelas a gente tem a soma dos ângulos internos igual a $180^{\circ}$. A gente tem isso como consequência do V postulado de Euclides.

Fonte: Dados da pesquisa - Episódio 4.

Acreditamos que o primeiro experimento possibilitou que os licenciandos internalizassem -por meio de uma situação prática- o conceito de paralelismo na Geometria Euclidiana e atribuírem significados para o conceito de paralelismo ao verificarem que a soma dos ângulos internos de um triângulo qualquer é uma das consequências do Postulado das Paralelas. Esse processo é constatado também através das falas dos participantes ao exporem que:

"A gente percebeu que são duas paralelas (mostrando a construção do triângulo realizado pelo grupo na folha de papel). Colocamos assim: qualquer triângulo construido entre duas paralelas a gente tem a soma dos ângulos internos igual a $180^{\circ}$. A gente tem isso como consequência do V postulado de Euclides". (LO 4, Episódio 4, 2019).

Na Figura 4 apresentamos imagens dos licenciandos desenvolvendo o experimento durante o encontro. Nesse dado momento eles buscaram demonstrar que a soma dos ângulos internos de um triângulo na Geometria Euclidiana é igual a $180^{\circ}$. 
Figura 4 - Verificação da soma dos ângulos internos de um triângulo qualquer na superfície plana
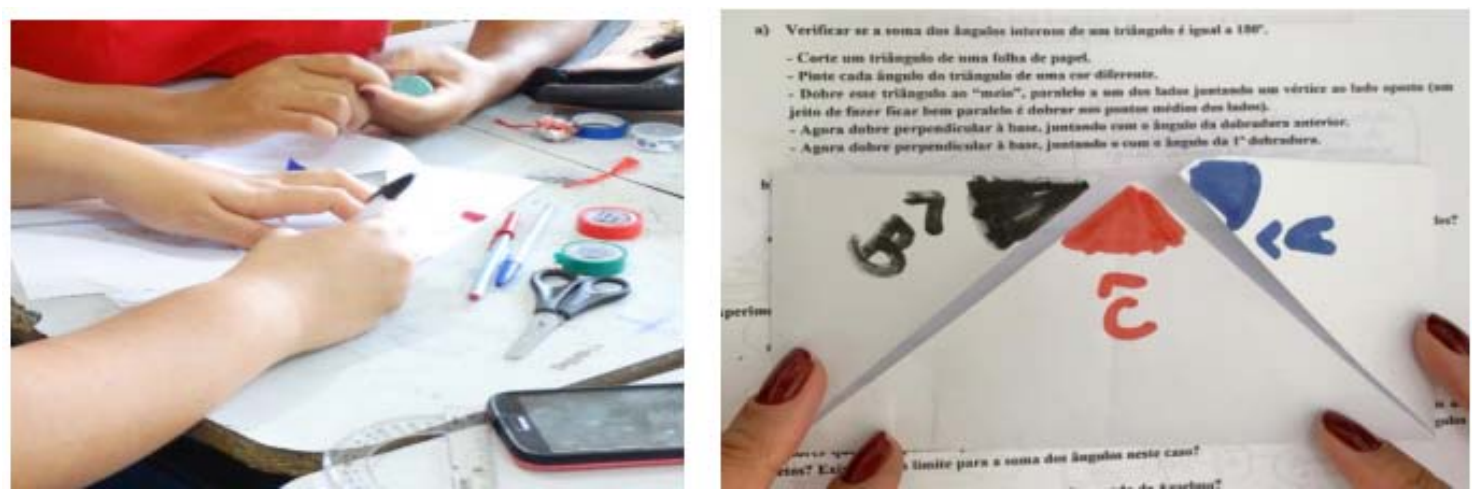

Fonte: Dados da pesquisa (2019).

Logo, os participantes compreenderam que as dobraduras realizadas a partir das medianas do triângulo construído uniram os vértices na base do mesmo formando um ângulo raso e que a nova figura formada representa um quadrilátero onde a base e a parte de cima da figura são paralelas. Assim, os licenciandos conseguiram relacionar que a soma dos ângulos internos de um triângulo na Geometria Euclidiana é uma consequência do paralelismo entre retas.

O segundo experimento consistiu na construção de triângulos em uma bola de isopor com o uso de fitas adesivas coloridas para descrever as geodésicas que forma os mesmos. A partir dessa construção esperávamos que os participantes comparassem os triângulos esféricos com o triângulo construído na folha de papel A4 e, por meio de suas diferenças, estabelecessem aspectos que pudessem determinar o tipo de superfície em que Anselmo se encontra.

Para melhor compreensão da formação de ângulos internos de um triângulo esférico construímos, como parte do experimento II, um instrumento para medir ângulos em superfície esférica. $\mathrm{O}$ transferidor esférico ${ }^{1}$ é um instrumento que quando manuseado de maneira adequada auxilia na aferição dos ângulos proporcionando maior confiabilidade para os dados investigados.

1 As informações sobre o processo de construção e utilização de um transferidor esférico foram consultadas no livro Atividades experimentais de matemática nos anos finais do ensino fundamental de autoria de Carlos Eduardo de Souza Campos Granja e José Luiz Pastore Mello, publicado em São Paulo: Edições SM, 2012.

\section{plurais}

Salvador, v.5, n.2 p.143-168, mai/ago. 2020 
A construção do transferidor esférico foi realizada pelos participantes da pesquisa durante o encontro como podemos observar na Figura 5.

Figura 5 - Construção do transferidor esférico
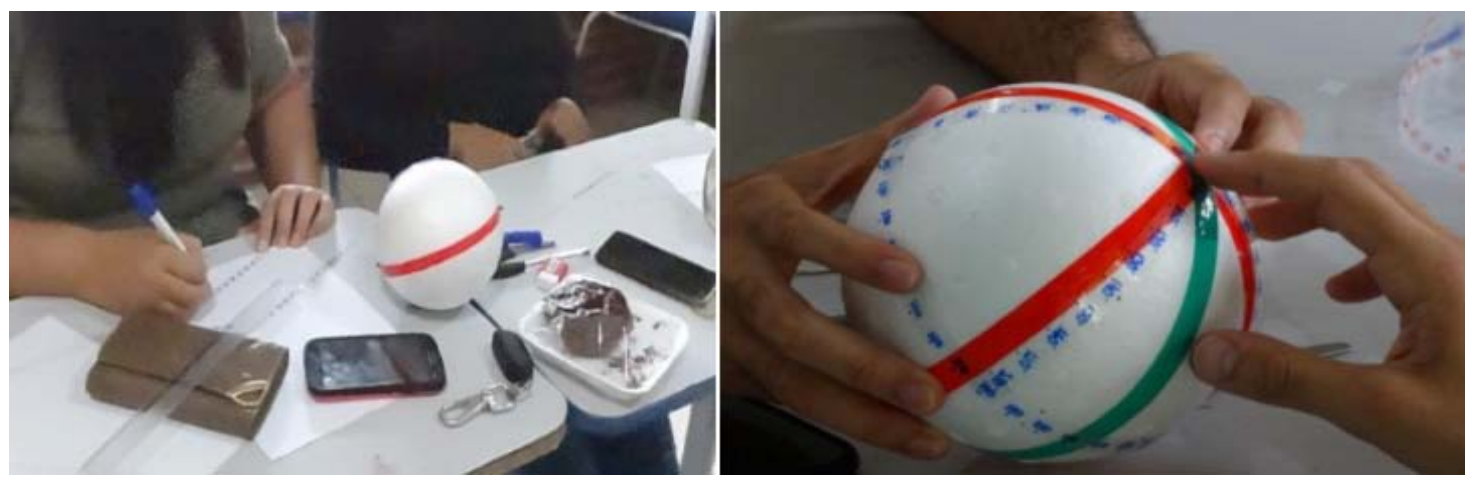

Fonte: Dados da pesquisa (2019).

A construção de um instrumento específico para a medição de ângulos na superfície esférica contribuiu para o entendimento dos participantes acerca da formação de ângulos em uma superfície esférica, uma vez que o manuseio do transferidor esférico proporcionou aos participantes certa segurança para afirmar que a soma dos ângulos internos de um triângulo esférico é maior que $180^{\circ}$. Em nossa análise, a ideia de um instrumento específico para medir ângulos em superfície esférica foi também mais um aspecto relevante para a aceitação da existência de um modelo geométrico diferente do euclidiano.

Mediante aquilo que nossa compreensão abarcou temos que as ações realizadas pelos participantes durante a construção do transferidor esférico proporcionou a troca de conhecimentos geométricos entre os mesmos, à medida que foram desenvolvendo estratégias para recortar, enumerar e colar, estes passaram a estabelecer as relações de uso do instrumento com a forma e medidas da bola de isopor. Assim, consideramos que o participante também produziu significados sobre os conteúdos geométricos ao confeccionar o transferidor esférico, uma vez que a apropriação de conceitos e de significados ocorre da atividade coletiva para a individual (VYGOTSKI, 2001).

Podemos observar, nos dizeres dos participantes, o quanto se tornou significativo o processo de construção do transferidor esférico:

\section{plurais}


"Foi nos dado materiais para construção de um transferidor esférico e nos surpreendemos, pois nunca havíamos visto um e ainda mais construirmos. Foi de grande experiência ter desenvolvido essa atividade com material concreto, pôr em prática todos os conceitos teóricos e nos fez ampliar a aprendizagem e vermos na prática como a geometria funciona”. (LD 3, RI 5, 2019).

Já no recorte apresentado na Cena 3 observamos que os licenciandos ao construírem os triângulos esféricos na bola de isopor constataram que a medida em que os triângulos aumentam as suas dimensões os ângulos internos também aumentam e, consequentemente, aumentam a área dos mesmos.

Cena 3: Discussão sobre as características de um triângulo esférico

PP - Utilizando a bola de isopor construa três triângulos esféricos um dentro do outro. $O$ que vocês perceberam? A soma dos ângulos internos do triângulo foram iguais, menores ou maiores de $180^{\circ}$ ?

Todos-Maiores.

$P P-O$ que seria um triângulo esférico?

$L B 3$ - Três geodésicas que se interceptam.

$P P-N a$ verdade elas sempre vão se interceptar. Então é a região formada por três geodésicas distintas.

$P P$ - O que podemos afirmar do mundo de Anselmo?

LB 3 - Que o mundo dele não é plano.

LO 4 - Que é esférico.

$P P$ - Mesmo que ele não tenha a certeza que ele é esférico, ele tem a certeza que não é plano. Eu queira perguntar para vocês... A medida que o triângulo vai crescendo na Geometria esférica os ângulos vão ...

LO 4 - aumentando também.

$P P-A$ área dele aumenta também?

LO 4 - A área?

LO 1 - A área aumenta.

$P P$ - Tem alguma relação com a Geometria plana?

Todos - Concordam que não.

PP - Esta pode ser uma das percepções de Anselmo que indica que não está no plano e sim numa esfera.

Fonte: Dados da pesquisa - Episódio 4. 
Em nossa compreensão, os participantes ao analisar a área e os ângulos internos de um triângulo esférico passaram a atribuir novos significados para a relação entre eles ao constatarem que à medida que a soma dos ângulos internos de um triângulo esférico aumenta sua área também aumenta, conduzindo-os a concluírem que não há semelhança de triângulos na Geometria Esférica.

"Analisarmos a área e os ângulos do triangulo esféricos percebemos que quanto maior a área maior os ângulos, ao contrário do que acontece na plana que os ângulos matem se os mesmo sendo assim não tem semelhanças de triângulos na geometria esférica pois os ângulos mudam de acordo com a sua área." (LD 2, RI 4, 2019).

Nesse contexto, compreendemos que o movimento realizado pelos participantes no Episódio 4 foi caracterizado pela ruptura dos mesmos com a ideia de um único modelo geométrico, pois ao internalizarem que a soma dos ângulos internos de um triângulo esférico é maior que $180^{\circ}$ foi possível compreender a partir da relação entre área e ângulos internos de um triângulo, que o modelo geométrico mais adequado para representar o espaço físico em que vive o personagem Anselmo é constituído pela Geometria Esférica.

\section{Considerações Finais}

As interações entre pesquisador-participante, participante-participante e participante-artefatos configuraram uma atividade de formação, na qual compreendemos que o processo de aprendizagem e a construção de conhecimentos por parte dos envolvidos foram constituídos na interação e comunicação entre os mesmos.

A Atividade Ensino criada por nós e apresentada nesse artigo foi pertinente para a produção de significados acerca do conhecimento geométrico não euclidiano, uma vez que as situações vivenciadas pelos participantes potencializaram ações que os mesmos não conseguiam realizar sozinhos.

As categorias de análises "Conflito - da validade lógica à validade empírica" e "Ruptura - do espaço euclidiano para outros espaços" nos permitiram acessar diversos significados que os licenciandos produziram para os conteúdos geométricos estudados, dando condições para negociarmos novos significados em uma perspectiva Histórico-Cultural na qual a construção 
do conhecimento geométrico se manifestou como uma produção humana, resultado de uma ação compartilhada entre licenciando/licenciando e licenciando/professor-pesquisador.

Desse modo, compreendemos que o movimento realizado pelos participantes foi caracterizado pela ruptura dos mesmos com a ideia de um único modelo geométrico. Pois, ao internalizarem que a soma dos ângulos internos de um triângulo esférico é maior que $180^{\circ}$, os estudantes tiveram a condição de afirmar que o modelo geométrico mais adequado para representar o espaço físico em que vive o personagem Anselmo é constituído pela Geometria Esférica. Além disso, os participantes ao analisar a área e os ângulos internos de um triângulo esférico passaram a atribuir novos significados para a relação entre eles, ao constatarem que a medida que a soma dos ângulos internos de um triângulo esférico aumenta sua área também aumenta, conduzindo-os a concluírem que não há semelhança de triângulos na Geometria Esférica.

Por tudo que foi exposto, compreendemos que a intervenção pedagógica realizada com os licenciandos foi constituída a partir dos princípios teórico-metodológicos da $\mathrm{AOE}$, como um modo de organização do ensino, em que o seu principal conteúdo foi estudar conceitos geométricos não euclidianos. O objetivo foi aferir a constituição do pensamento teórico dos licenciandos no movimento de apropriação de conceitos geométricos (euclidianos e não euclidianos) a partir da verificação empírica dos mesmos em diferentes espaços geométricos.

\section{REFERÊNCIAS}

ANTUNES, Marcelo Carvalho. Uma possível inserção das Geometrias não-Euclidianas no Ensino Médio. 54 f. Monografia (TTC) - Universidade Federal do Rio Grande do Sul. Porto Alegre: 2009.

ARAÚJO, Elaine Sampaio. Da Formação e do Formar-se: a atividade de aprendizagem docente em uma escola pública. 2003. 173 f. Tese (Doutorado em Educação) - Faculdade de Educação da Universidade de São Paulo, São Paulo, 2003.

DANIELS, H. Vygotsky e a Pedagogia. São Paulo: Loyola, 2003.

KOPNIN, P. V. A dialética como lógica e teoria do conhecimento. Rio de Janeiro: Civilização Brasileira, 1978.

\section{P/Ulails ${ }_{\text {revista multidisciolinar }}$ Salvador, v.5, n.2 p.143-168, mai/ago. 2020}


LEONTIEV, A. N. Actividad, conciencia y personalidad. Buenos Aires: Ediciones Ciencias Del Hombre, 1978.

LEONTIEV, A. Et al. Linguagem, Desenvolvimento e Aprendizagem. São Paulo: Icone, 1988.

LOPES, A. R. L. V.; VAZ, H. G. B. O Movimento de Formação Docente no Ensino de Geometria nos Anos Iniciais. Educação \& Realidade, Porto Alegre, v. 39, n. 4, p. 1003-1025, 2014.

MORETTI, V. D. Professores de matemática em atividade de ensino. Uma perspectiva histórico-cultural para a formação docente. 2007. 208f. Tese (Doutorado em Educação) Universidade de São Paulo, São Paulo, 2007.

MORETTI, V. D. O problema lógico-histórico, aprendizagem conceitual e formação de professores de matemática. Poiésis, Tubarão, número especial, p. 29-44, 2014.

MOURA, M. O.; Et al. A atividade orientadora de ensino como unidade entre o ensino e a aprendizagem. In: M. O. Moura (org.). A atividade pedagógica na teoria histórico-cultural. Brasília, DF: Liber, 2010.

MOURA, M. O. Controle da variação de quantidades: Atividades de ensino. São Paulo: FEUSP, 1996.

MOURA, M. O. A atividade de ensino como ação formadora. In: Castro, A. D.; Carvalho, A. M. P. (Org.). Ensinar a ensinar: didática para a escola fundamental e média. São Paulo: Thomson, 2002.

MOYSÉS, L. Aplicações de Vygotsky à educação matemática. Campinas: Papirus, 1997.

NASCIMENTO, C. P. A organização do ensino e a formação do pensamento estético-artístico na teoria histórico-cultural. 2010. 250 f. Dissertação (Mestrado em Educação) - Faculdade de Educação - USP, São Paulo, 2010.

PETIT, J. P. As Aventuras de Anselmo Curioso - Os Mistérios da Geometria. Lisboa: Publicações Dom Quixote, 1982.

POZEBON, S.; LOPES, A. R. L. V.; FRAGA, L. P.; HUNDERTMARCK, J. A formação de futuros professores dos anos iniciais do ensino fundamental: uma discussão a partir de uma atividade de ensino de geometria. Experiências em Ensino de Ciências, v.8, n. 3, 2013.

\section{plurais}


ROSA, J. E.; Et al. As Particularidades do Pensamento Empírico e do Pensamento Teórico narganização do Ensino. In: MOURA, Manoel Oriosvaldo (org.). A Atividade Pedagógica na Teoria Histórico-Cultural. Brasília: Líber, p. 67-80, 2010.

SAVIANI, D. Educação: do senso comum à consciência filosófica. 13. ed. Campinas: Autores Associados, 2000.

VAZ, H. G. B. A Atividade Orientadora de Ensino como organizadora do trabalho docente em matemática: a experiência do Clube de Matemática na formação de professores dos anos iniciais. 2013. 153 f. Dissertação (Mestrado em Educação) - Universidade Federal de Santa Maria-RS, 2013.

VYGOTSKY, L. S. Pensamento e Linguagem. São Paulo, Martins Fontes, 1987.

Recebido em: 20 de junho de 2020

Inserido em: 10 de agosto de 2020 .

Esta obra está licenciada com uma Licença Creative Commons Atribuição 4.0 Internacional. 